\title{
Robótica Educacional e Resolução de Problemas: uma abordagem microgenética da construção do conhecimento ${ }^{1}$
}

\section{Educational Robotics and Problem Solving: a microgenetic approach to knowledge construction}

DOI: 10.46814/lajdv3n1-021

Recebimento dos originais: $30 / 10 / 2020$

Aceitação para publicação: 23/12/2020

\section{Cristiane Pelisolli Cabral}

Mestrado PPGEDU-UFRGS (doutoranda em Educação PPGEDU-UFRGS)

Instituição de atuação atual Universidade Federal do Rio Grande do Sul - UFRGS

Endereço completo Faculdade de Educação - FACED

Av. Paulo Gama, 110 (prédio 12-220, sala 1001)

90046-900 Porto Alegre RS Brasil

Tel (051) 3308 - 3425

E-mail pelisolli@gmail.com

\begin{abstract}
RESUMO
O presente estudo de caso objetivou investigar as estratégias cognitivas de resolução de problemas em Robótica Educacional (RE) com auxílio do kit semiestruturado LEGO Mindstorms® ${ }^{\circledR} 9793$ e programação RoboLab®. Com base na teoria da Microgênese Cognitiva de Bärbel Inhleder foram investigadas as estratégias cognitivas do sujeito psicológico para resolver problemas de Robótica Educacional. O estudo baseou-se na análise do caso de um aluno de Robótica Educacional em nível de Ensino Fundamental, que resolveu individualmente um problema de RE com o kit. O procedimento de resolução do problema foi gravado em vídeo e analisado com suporte do software Transana®. A análise do procedimento do sujeito em situação de resolução de problema de Robótica Educacional com enfoque nas microgêneses cognitivas possibilitou visualizar como acontece a construção das estratégias cognitivas de resolução de problemas através da elaboração da representação mental e da construção ou atualização dos esquemas familiares na ação do sujeito sobre os objetos e sobre si mesmo no nível operatório concreto.
\end{abstract}

Palavras chave: Robótica Educacional, Resolução de Problemas, Microgênese Cognitiva, Epistemologia Genética, Análise Microgenética, Estratégia Cognitiva, Sujeito Psicológico.

\begin{abstract}
The present work investigated the cognitive strategies for problem solving in Educational Robotics (ER) with the LEGO® Mindstorms 9793 kit and programming with RoboLab®. Based on the theory of cognitive microgenesis, by Bärbel Inhleder, sought to investigate the cognitive strategies of a psychological subject to problem solving of Educational Robotics. The study was based on case analysis of one subjects, student of Educational Robotics in basic education level, which individually resolved a problem with the ER LEGO® kit. The procedure for solving the problem was filmed and analyzed with the software Transana ${ }^{\circledR}$. The analysis of the subjects procedure in a situation of problem solving on Educational Robotics with focus on cognitive microgeneses allowed to visualize how happen the construction of strategies for problem solving through the development of mental

\footnotetext{
${ }^{1} \mathrm{O}$ presente artigo é um estudo piloto para a dissertação de mestrado com mesmo título da autora, defendida e aprovada em dezembro de 2010 pelo Programa de Pós Graduação em Educação (PPGEDU) da Universidade Federal do Rio Grande do Sul (UFRGS).
} 
representation and construction or upgrading of familiar schemes through the action of the subject about objects and about himself in the concrete operational level.

Keywords: Educational Robotics, Problem Solving, Microgenesis Cognitive, Genetic Epistemology, Microgenetic Analysis, Strategy Cognitive Psychology Subject.

\section{INTRODUÇÃO}

A Robótica Educacional (RE) é uma atividade que reúne construção e programação de robôs e pode ser desenvolvida em nível escolar utilizando kits semi-estruturados comercializados no mercado brasileiro ou até mesmo sucata eletrônica. A aula geralmente é direcionada para a construção de um protótipo e posteriormente é feita a programação através do computador utilizando um software de programação. A montagem é o momento onde os alunos se utilizam de blocos, peças ou placas que se movimentarão autonomamente após serem programados através do software no computador. A atividade pode se desenvolver individualmente, em duplas ou em grupo o que promove o trabalho cooperativo e integrado. Além de ser uma atividade educacional que trabalha com a construção e programação de objetos concretos, também possibilita a reflexão por meio da resolução de uma série de problemas desencadeados ao longo do processo de criação.

O material utilizado nesta investigação é o kit semi-estruturado LEGO Mindstorms® 9793, desenvolvido por Papert e colaboradores, e comercializado pela LEGO® desde 1998. Trata-se de uma caixa com divisórias contendo 830 peças entre elas blocos plásticos, vigas, pranchas, engrenagens, rodas, eixos, cabos, sensores (sensor de toque, luz, temperatura), motores, entre outros, e um bloco programável. O RCX, ou “tijolo programável” (RESNICK et al, 1996), é um bloco que funciona como microcontrolador autônomo e pode ser programado usando um computador e o software de programação RoboLab®. Ele utiliza sensores para obter entradas do ambiente, processar dados e comandar motores e lâmpadas para que liguem e desliguem. Cinco programas podem ser armazenados numa unidade RCX, um em cada slot do RCX, totalizando 1.500 comandos (ROBOLAB, 2003). O RCX funciona através da programação com o software RoboLab® baseado em comandos representados por ícones. Depois de selecionar os comandos, os alunos transferem a programação para o RCX através de um transmissor infravermelho conectado ao computador. O tipo de interface e a linguagem gráfica do RoboLab® torna a tarefa de programação bastante acessível para alunos do Ensino Fundamental.

A RE no Ensino Fundamental também é uma atividade com aspectos lúdicos onde os sujeitos se deparam com uma porção de peças que possibilitam o planejamento e a construção de objetos que simulam o real, tais como automóveis, máquinas, animais, entre outros, que depois de construídos e 
programados são protagonistas de brincadeiras e jogos criados pelos próprios alunos. Contudo, tais objetos demandam grande esforço cognitivo para sua construção, programação e testagem objetivando o funcionamento autônomo tal qual se projetou inicialmente.

Entendo que a atividade da RE pode promover a ação física e mental do sujeito, tal como nos disse Piaget na sua teoria da Epistemologia Genética, além de ser uma atividade muito motivadora para os alunos uma vez que trabalha com a construção de objetos, programação e reconstrução permanente dos esquemas de ação através da resolução de problemas decorrentes da montagem e programação desses objetos. Nesse sentido, faz-se necessário investigar detalhadamente os processos cognitivos envolvidos nessa atividade, com intuito de aperfeiçoar seu uso no meio escolar impulsionando os mecanismos da construção do conhecimento de cada sujeito.

\section{FUNDAMENTAÇÂO TEÓRICA}

Jean Piaget (1896-1980), teórico da Epistemologia Genética, dedicou-se a pesquisas para explicar os mecanismos da construção do conhecimento e sua questão norteadora era responder como passamos de um nível menor para outro maior de conhecimento. O termo "Epistemologia" refere-se ao estudo do conhecimento e, no caso da teoria de Piaget, "Genética" refere-se à gênese, ou origem desse conhecimento. Contrapondo-se às teorias Epistemológicas Empirista e Apriorista, Piaget escreveu ao longo de suas obras que a origem do conhecimento é uma construção realizada através das ações físicas (agindo sobre os objetos) e mentais (reorganizando as estruturas mentais) do sujeito. Piaget interessou-se por problemas de epistemologia e teorizou com base naquilo que considerou universal em qualquer sujeito, ou seja, as estruturas cognitivas. Bärbel Inhelder colaborou com Piaget em várias investigações sobre as grandes categorias do conhecimento, mas posteriormente focou seus estudos em como os sujeitos constroem individualmente, e por isso, de forma diferenciada, seus conhecimentos. Inhelder dedicou-se a investigar o percurso das descobertas da criança para resolver problemas, para tanto, se usou de uma análise pormenorizada da ação de indivíduos no momento em que resolvem determinadas situações, que se apresentam como problema, na busca de uma solução.

A presente investigação busca fundamentos teóricos na Epistemologia Genética de Jean Piaget com enfoque nas Microgêneses Cognitivas de Bärbel Inhelder et al (1996) para investigar os processos cognitivos durante a resolução de problemas de Robótica Educacional com o intuito de refletir sobre as estratégias individuais envolvidas nesse processo uma vez que parece ser um momento de intensa criatividade do sujeito. Portanto, o problema de pesquisa que se coloca é o seguinte: Que estratégias cognitivas são utilizadas pelos sujeitos na resolução de problemas em Robótica Educacional? O problema se desdobra nas seguintes questões: Qual é a sequência e o encadeamento de ações realizadas ao longo do procedimento de resolução? Qual(Quais) a(as) representação(ções) que o sujeito elabora 
ao longo do processo de resolução? Qual(quais) a(as) centração(ões) que o sujeito realiza ao longo do procedimento de resolução?

A análise baseada no estudo das microgêneses cognitivas de Inhelder et al (1996) deve assegurar uma comunhão de abordagem onde a análise categorial do sujeito epistêmico e a análise funcional do sujeito psicológico sejam igualmente legítimas e complementares compartilhando com Piaget a idéia de um sujeito ativo e construtor que participa ativamente do conhecimento do universo e de si próprio. Para analisar o procedimento de resolução de problemas do sujeito é necessário atentar para os seguintes tópicos de observação sugeridos por Inhelder et al (1996): Focar nos "Novos Observáveis"2, ou seja, as seqüências de ações e seus encadeamentos; Elucidar relações entre procedimentos de descoberta e sistemas de compreensão; Verificar como se organiza os passos em direção ao objetivo pretendido; Levantar hipóteses acerca dos processos que sustentam a orientação dos passos percorridos pelo sujeito e Inferir modelos subjacentes e sua organização funcional.

\section{METODOLOGIA}

A abordagem escolhida para esta investigação é a pesquisa qualitativa que busca obter dados descritivos através do contato direto do pesquisador com o objeto de estudo. A escolha por esse tipo de abordagem justifica-se na medida em que somente ela possibilita a análise do processo cognitivo envolvido na resolução de problemas proposta para essa investigação. Uma abordagem qualitativa na perspectiva do estudo de caso tendo como referência os estudos de Inhelder et al (1996) buscará analisar o progresso cognitivo macrogenético apoiado em análises detalhadas das condutas do sujeito, pois elas evidenciam características do processo interativo entre sujeito e objeto.

O experimento utilizado na pesquisa é chamado de "problema" e a resolução do problema é entendida aqui como um momento privilegiado para estudar processos cognitivos funcionais. $\mathrm{O}$ experimento consiste em levar um carro construído com peças LEGO®, “com problemas mecânicos” até uma oficina mecânica, representada por uma casa construída também com peças LEGO®, localizada sobre um espaço plano chamado de "mesa" há cerca de um metro e meio de distância. Será solicitada ao sujeito uma previsão da construção do objeto com o objetivo de verificar os esquemas cognitivos construídos anteriormente pelo sujeito. Dessa forma a pesquisadora solicitará que o sujeito conte para ela como está imaginando o objeto que irá levar o carro até a oficina. A atitude do experimentador é a de um observador durante o curso da resolução do problema, pois ele dá a tarefa ao sujeito, deixa-o livre e abstêm-se de intervir ativamente, mas deve estar muito mais atento à

\footnotetext{
${ }^{2}$ São "novos Observáveis” em relação às categorias de análise do Método Clínico Piagetiano. Os novos observáveis são gerais em todos os sujeitos, os conteúdos, estruturas acionadas é que são individuais.
} 
observação dos comportamentos tais como expressões faciais, balbucios, respiração, gestos e mímicas que acompanham os processos de resolução de problemas. É necessário intervir pouco para que o sujeito fique livre para atualizar os esquemas cognitivos que lhe pareçam adequados para a situação.

A coleta de dados na abordagem qualitativa baseada na metodologia proposta por Inhelder et al (1996) é realizada através de gravação em vídeo para que possa ser retomada tantas as vezes quanto forem necessárias, pois só progressivamente poderemos identificar recortes que o sujeito faz para revelar seus procedimentos ou encadeamento de ações. Além disso, gravando em vídeo pode-se retomar a análise revendo o desempenho do sujeito, pois a visualização repetida torna a descrição mais precisa. Para a análise dos dados dessa investigação foi utilizado um software específico para análise qualitativa de dados chamado Transana ${ }^{\circledR}$ que é um software direcionado a pesquisadores que desejam analisar materiais em vídeo digital ou áudio. Ele permite analisar e gerenciar dados através de transcrições, ligações entre transcrição e vídeo, produção de clips, atribuição de palavras-chave para clips, organização e reorganização dos clipes, criação de coleções de inter-clips, exploração das relações entre as palavras-chave, além de possibilitar o compartilhamento da análise com outras pessoas do grupo de pesquisa, se for o caso.

\section{ANÁLISE DE CASO}

A seguir apresenta-se uma análise detalhada do procedimento de resolução do problema de um sujeito $^{3}$ aluno de Robótica Educacional no Ensino Fundamental de uma escola pública municipal da periferia de Porto Alegre/RS.

O experimento inicia com as instruções sendo lançadas ao sujeito que verbaliza que construirá um robô parecido com o robô "tirando a mesa" construído anteriormente por ele nas aulas de robótica. Diz também que vai usar "muitas peças" na montagem do robô tais como: vigas, blocos, rodas, engrenagens, buchas e eixos. Observa-se que o sujeito elaborou uma representação inicial para resolver o problema baseado nas construções realizadas por ele nas aulas de robótica. Observa-se também que o sujeito construiu anteriormente alguns esquemas de procedimento para realizar a montagem, pois verbaliza quais são as peças necessárias para a construção do protótipo. A pedido da pesquisadora o sujeito representa através do desenho a imagem mental elaborada por ele como solução para o problema. Depois de concluir o desenho o sujeito explica sua representação da seguinte forma " $S$ : ele é retangular, tem umas rodas médias e tem tipo uns ganchinhos assim”. Depois disso o sujeito inicia a montagem do objeto.

\footnotetext{
${ }^{3}$ Sexo: Masculino; Idade: 11 anos; Tempo que freqüenta as aulas de robótica: 1 ano 6 meses; Tempo total usado para solucionar o problema: 43 minutos.
} 
Na primeira etapa da conduta do sujeito ele constrói a base do robô acionando um esquema familiar. Ao longo do seu procedimento o sujeito realiza uma centração para resolver o encaixe das engrenagens no motor, atuando através de procedimentos de descoberta e dessa forma atualizando o esquema acionado inicialmente para a construção da base. Abaixo podemos verificar o procedimento de construção da base do robô orientado por um esquema familiar que vai sendo atualizado para a situação específica, no caso, das engrenagens:

S: $x<289697>(0: 04: 49.7)$ ((pega RCX, conecta vigas, mede vigas, coloca conectores, tira, pega pranchas, pega mais pranchas, conecta nas vigas, conecta motor, conecta viga, observa, mede RCX,desmonta, remonta,coloca engrenagem, observa, coloca eixo atravessado na viga, conecta eixo e engrenagem, tira, conecta as engrenagens do motor e do eixo, desmonta, recoloca o motor em contato com as engrenagens, coloca rodas, fixa com buchas, observa, gira a engrenagem, observa, faz o mesmo do outro lado da viga, eixos, buchas, rodas e buchas, desencaixa, suspira fundo, desmonta, observa, troca as engrenagens, recoloca as rodas, testa empurrando prá lá e prá cá,vibra, seleciona mais vigas, conecta, fixa na lateral das vigas, faz o mesmo do outro lado, coloca o RCX, tira, pega rodas, pega eixo, coloca na frente, tira, alonga eixo com luvas, coloca buchas, gira o eixo, coloca buchas, coloca rodas nos eixos, testa, troca as rodas por rodas maiores, troca as quatro rodas, testa empurrando, coloca buchas, liga o RCX, desliga, coloca na base, aperta, testa, coloca cabos, liga o motor ao RCX)) Tá quase, tá quase, tá quase, feito! Tomara que esteja funcionando, agora, deixa eu ver aqui ((empurra o robô com as mãos $)) \propto<1922173>(0: 32: 02.2)$

O sujeito verbaliza espontaneamente "S: (...) Tá quase, tá quase, tá quase, feito!” marcando a finalização da primeira etapa e o encadeando da segunda etapa. Na segunda etapa o sujeito parte para a programação do objeto abrindo o programa Robolab® na tela do computador e construindo sua primeira programação orientada por um esquema familiar.

Depois de construir a programação e transferi-la para o RCX do robô o sujeito verbaliza " $S: A h$ me esqueci de uma coisinha aqui”. Então conecta vigas em L nas laterais do RCX. Através dessa conduta observa-se que o sujeito não realiza uma centração para construir um anexo para o robô, pois a base e o anexo do robô para esse sujeito compõem um "todo". O sujeito apenas atualiza o esquema inicial de construção da base onde o anexo já faz parte e conecta as vigas em L nas laterais do RCX. Portanto, a partir dessa conduta, incluindo ela, pode-se dizer que o sujeito inicia a terceira etapa da resolução do problema onde resolve os problemas da montagem e programação na busca da solução final.

Na terceira etapa de resolução do problema, iniciando com o anexo da garra nas laterais do RCX o sujeito passa a realizar testes no robô e a ajustar o tempo da programação para levar o carro até a casa. Na primeira testagem o sujeito posiciona o carro na direção da casa sem o carro na frente do robô e liga. O robô se movimenta e se choca contra a casa. O sujeito então posiciona de novo o robô no ponto inicial ainda sem o carro na frente e liga, enquanto o robô se movimenta na direção da casa o 
sujeito conta os segundos até chegar bem próximo da casa. Ele volta para a tela do computador e modifica a programação para 6 segundos de tempo de giro do motor.

O sujeito transfere a programação para o RCX do robô e testa novamente. Posiciona o robô sem o carro e liga o robô, ele se movimenta na direção da casa e se choca contra ela. Ele diminui novamente o giro do motor para 5 segundos e transfere novamente. Posiciona e liga, o robô se movimenta e pára bem próximo da casa. O sujeito questiona a pesquisadora "S: Tá bom aqui sora?" ao que a pesquisadora responde " $P$ : Tu que sabe quando está bom".

O sujeito então aumenta o tempo de giro do motor para 5,5 segundos e transfere para o RCX. Testa mais uma vez sem o carro e chega muito perto da casa. O sujeito reposiciona o robô agora com o carro na frente e o robô pára antes de tocar na casa. O sujeito verbaliza "S: mais um pouquinho!” $\mathrm{E}$ modifica para 6,0 segundos o tempo do giro do motor. Testa novamente com o carro e diz: "S: Mais um pouco!' Nesse momento a pesquisadora questiona o sujeito: P: Antes tava chegando e agora não tá, porque? Ao que o sujeito responde: S: Por causa do peso do carro. A pesquisadora fez esse questionamento para confirmar se o sujeito havia considerado o peso do carro como fator de alteração da programação. O sujeito então modifica mais uma vez a programação. Transfere a programação para o RCX do robô. Testa mais uma vez e o robô desvia do trajeto se chocando contra a parede da mesa. Posiciona novamente e liga, o robô desliza na direção da casa e pára bem próximo a ela. O sujeito exclama: S: Consegui! Nesse momento o experimento é dado como encerrado.

\section{CONCLUSÃO}

A estratégia de resolução do problema desse sujeito pode ser dividida em três etapas encadeadas. Depois de elaborar a representação inicial para resolver o problema o sujeito aciona um esquema familiar para construir a base do robô $(\mathrm{C} 1)$. A conduta se desenrola até que o sujeito realiza uma centração para resolver o problema do encaixe das engrenagens na base do robô (C2)|. Tal centração faz com que o sujeito atualize o esquema acionado inicialmente através de procedimentos exploratórios. Na etapa dois o sujeito constrói a programação do objeto guiado por um esquema familiar (C3). Na terceira etapa realiza uma correção na construção onde havia esquecido de conectar as garras do robô (C4), em seguida passa a testar o robô e ajustar a programação (C5) através de procedimentos de descoberta quando dá por encerrada a resolução do problema. A Figura 5 representa a tentativa de sistematizar o procedimento de resolução do problema do sujeito:

Segundo Inhelder et al (1996), o sujeito deve fazer ajustes mentais, imaginando as conseqüências de certas ações. $\mathrm{O}$ ajuste se dá sempre em relação à uma ideia diretriz que assegura um primeiro planejamento das ações, mas que é a seguir modificada a partir dos resultados destas ações. Esta idéia garante uma ligação entre a representação do objetivo e os procedimentos a efetuar. As 
sucessões rápidas permitem ao sujeito informar-se sobre o resultado de suas ações, julgar a sua adequação e fazer ajustes na aplicação dos esquemas. Durante a resolução de um problema, parece que o sujeito avalia constantemente a adequação de suas previsões e de suas manobras.

Como podemos observar, a investigação das microgêneses cognitivas põe em evidência os processos funcionais da cognição que intervém quando o sujeito aplica seus conhecimentos a contextos particulares. Mais do que as formas que o raciocínio pode tomar nas diferentes fases do desenvolvimento cognitivo, os estudos sobre a dimensão local da atividade cognitiva do sujeito podem ser úteis à educação destacando as etapas de compreensão de um conhecimento realizadas pelo sujeito, detalhando as hipóteses, avanços, retrocessos, enfim, o desenrolar das descobertas de cada indivíduo no processo de resolução de problemas. 


\section{REFERÊNCIAS BIBLIOGRÁFICAS}

INHELDER, Bärbel; CELLÉRIER, Guy (e colaboradores) O desenrolar das descobertas da criança: um estudo sobre as microgêneses cognitivas. Porto Alegre: Artes Médicas, 1996.

PAPERT, Seymour. A máquina das crianças: repensando a escola na era da informática. Porto Alegre: Artmed, 2008.

, Seymour. LOGO: computadores e educação. SP: Brasiliense, 1985.

PIAGET, Jean e INHELDER, Bärbel. A Psicologia da Criança. RJ: Bertrand Brasil, 1999.

Médicas, 1985.

Jean. O possível e o necessário (Vol I): evolução dos possíveis na criança. Poa: Artes , Jean. O possível e o necessário (Vol II): evolução dos necessários na criança. Poa: Artes Médicas, 1986.

, Jean. A Tomada de Consciência. São Paulo: Melhoramentos, 1977.

, Jean. Fazer e Compreender. São Paulo: Melhoramentos, 1978.

RESNICK M., MARTINF., R. SARGENT R., AND SILVERMAN B. Programmable Bricks: toys to think with Accepted for publication April 4, 1996. Disponível em: https://www.research.ibm.com/journal/sj/353/sectionc/martin.html. Acessado em agosto de 2010. ROBOLAB Revista. Curitiba: ZOOM Editora educacional, 2003. 